\title{
Winter-spring cyclonic variability in the Mediterranean-Black Sea region associated with global processes in the ocean-atmosphere system
}

\author{
E. N. Voskresenskaya and V. N. Maslova \\ Marine Hydrophysical Institute, Sevastopol, Ukraine \\ Received: 6 December 2010 - Revised: 20 June 2011 - Accepted: 4 August 2011 - Published: 30 August 2011
}

\begin{abstract}
Using global NCEP/NCAR reanalysis data set on $1000 \mathrm{hPa}$ geopotential height (1948-2006), cyclones in the Mediterranean and Black Sea regions were detected and their main characteristics (frequency, depth, integrated area) were calculated. Analysis of their interannual-multidecadal variability in JanuaryMarch associated with global processes in the ocean-atmosphere system was done. It was shown that North Atlantic Oscillation (NAO) manifests in the Black Sea region mainly in the variability of frequency of cyclones while in the Mediterranean - in the interannual anomalies of cyclones' depth and area. Joint NAO and El Nino - Southern Oscillation (ENSO) influence is responsible for about $20-45 \%$ of cyclones' frequency variance in the Black Sea region, and in the Mediterranean region for up to 10-25 and 20-30\% of the depth and area variance, accordingly. As a result of using a new approach to study ENSO manifestations based on El Nino classification, correlation coefficients between characteristics of cyclones and Southern Oscillation index (SOI) increase at least twice.

The influence of the Pacific Decadal and Atlantic Multidecadal Oscillations on variability of cyclonic activity in the Mediterranean-Black Sea region manifests in considerable differences of cyclones' characteristics and their typical location.
\end{abstract}

\section{Introduction}

The main climatic modes of the global ocean-atmosphere system are the North Atlantic Oscillation (NAO) and El Nino-Southern Oscillation (ENSO) on the interannual scale, while on the decadal-multidecadal scale they are the Pacific Decadal Oscillation (PDO) and Atlantic Multidecadal Oscillation (AMO) as it was shown for example by Barnston and Livezey (1987) and Enfield et al. (2001). Each of these modes has its specific regional manifestations, which are the most pronounced in cold half-year. Cyclonic activity over the Atlantic-European region including the MediterraneanBlack Sea region is an important indicator of regional climate/weather anomalies in this period of year.

NAO manifestations in the interannual variability of frequency of cyclones in the Black Sea region were analyzed in Polonsky et al. (2007). The analysis for different areas of the Mediterranean was done, for example, in Trigo

Correspondence to:

E. N. Voskresenskaya

(elena_voskr@mail.ru) et al. (2003), Lionello et al. (2006), Guijarro et al. (2006), Pinto et al. (2009). Regional weather-climate anomalies in the Atlantic-European region associated with ENSO were studied, for instance, in Mariotti et al. (2002), Mathieu et al. (2004) whereas ENSO influence on cyclonic activity in the Mediterranean-Black Sea region was not studied yet.

PDO impact on Atlantic-European region was shown in decadal variability of river run-offs and some hydrometeorological characteristics for example by Voskresenskaya (2003), Pekarova et al. (2006). AMO manifestations in the Atlantic-European region were found in large scale temperature and sea level pressure anomalies (Enfield and MestasNunez, 1999), in number and intensity of tropical (Kerr, 2005) and extratropical (Polonsky, 2008) cyclones in the North Atlantic region and some other characteristics.

However, there is still no complex analysis of cyclonic activity in the Mediterranean-Black Sea region in the context of global interannual-multidecadal variability. Taking into account specific seasonality of cyglogenesis in the Mediterranean (as shown in Trigo et al., 1999) and that most prominent manifestations of the above-mentioned signals in the 


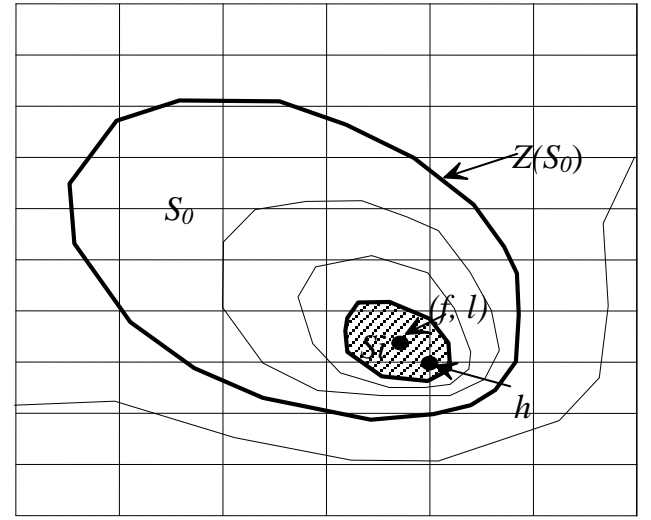

Figure 1. Isobar contour chart. $(f, l)$ - coordinates of the barycenter, $Z\left(S_{0}\right)$ - the last closed isobar contour, $S_{0}$ - an area of the figure delimited by the last closed isobar contour, $S_{i}$ - an area of the figure delimited by the first closed isobar contour, $h-$ a grid point nearest to cyclone's barycenter (after Bardin, 1995).

North Atlantic-European hydrometeorological fields are observed in mature winter-early spring (see for example Polonsky and Voskresenskaya, 1994), the aim of present paper is to study the contribution of NAO, ENSO, PDO and AMO in interannual-multidecadal variability of cyclonic activity in the Black Sea region, Western and Eastern Mediterranean in January-March.

\section{Data and methods}

On the basis of the daily NCEP/NCAR reanalysis data sets on $1000 \mathrm{hPa}$ geopotential height on a grid $2.5^{\circ} \times 2.5^{\circ}$ for the synoptic term 00:00 h GMT in 1948-2006 using the procedure of cyclones' detection by Bardin (1995), time series of the main characteristics (frequency, depth and area) of Mediterranean-Black Sea cyclones were obtained.

The procedure of cyclones' detection is the following. At first the identification algorithm finds all local minima and for each minimum determines a domain of low pressure bounded by closed isobars (see Fig. 1). Then the coordinates of the center of cyclone $(f, l)$ are calculated as a geometrical center of the figure delimited by the first closed isobar contour.

The relative frequency is defined for each considered time interval (specifically one day) as the ratio of the number of cyclones in a given square to the total number detected in the selected period of time (namely one month). The depth of cyclonic eddy is defined as the absolute value of pressure drop between the center of the domain and the last closed isobar (step of isobars is $1 \mathrm{hPa}$ ). The area $(A)$ of a cyclonic eddy is defined as the area bounded by the last closed isobar. Obtained cyclones characteristics were averaged over the three regions: the Western Mediterranean, Eastern Mediterranean and Black Sea region (see Fig. 2).

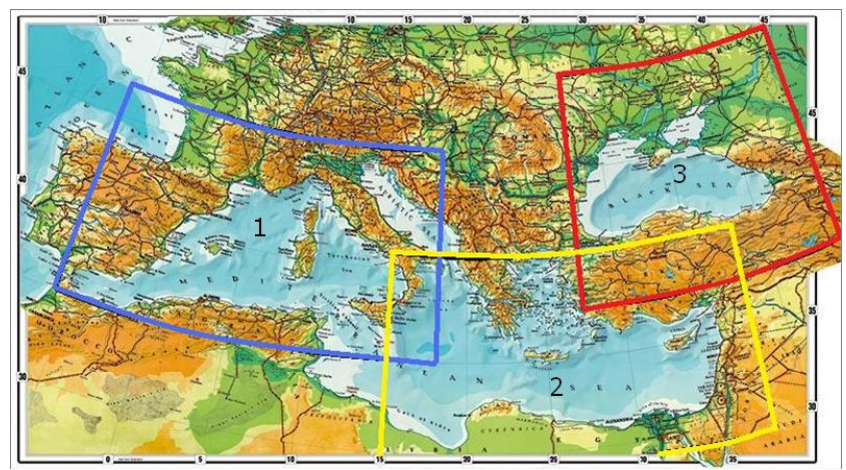

Figure 2. Boundaries of the studied regions: 1 - Western Mediterranean $\left(35-47^{\circ} \mathrm{N}, 6-18^{\circ} \mathrm{E}\right), 2$ - Eastern Mediterranean $\left(29-41^{\circ} \mathrm{N}\right.$,

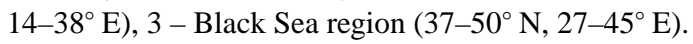

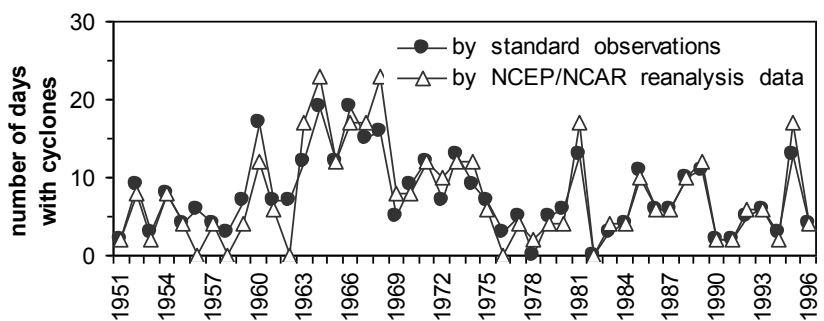

Figure 3. Number of days with cyclonic conditions in the Black Sea region in November obtained using NCEP/NCAR reanalysis data sets and composite-kinematic maps of the Ukrainian Hydrometeorological Service.

Quality control based on comparison of number of days with cyclones selected from NCEP/NCAR reanalysis and the same characteristic from composite-kinematic maps of the Ukrainian Hydrometeorological Service was done. Figure 3 demonstrates a good agreement between graphs of analyzed series (correlation coefficient $r=0.91$ ).

As the indicators of global interannual to multidecadal variability, monthly indices of NAO, Southern Oscillation (SOI), PDO and AMO were used.

Standard methods of correlation and composite analyses were used to estimate the connection between variability of the cyclones' characteristics and climatic modes.

As an additional independent source of comparison, maps of the trajectories of cyclones for certain periods were obtained using the Atlas of extratropical storm tracks in 1961-1998 (available online at: http://data.giss.nasa.gov/ stormtracks/). Daily NCEP/NCAR reanalysis dataset on the $500 \mathrm{hPa}$ geopotential height were used for composite analyses. 
Table 1. Monthly correlation coefficients between the characteristics of cyclones in all studied regions and the NAO index. Coefficients significant on $95 \%$ confidence level are set off in bold font.

\begin{tabular}{|c|c|c|c|c|c|c|c|c|c|}
\hline \multirow{2}{*}{ Period } & \multicolumn{3}{|c|}{ Western Mediterranean } & \multicolumn{3}{|c|}{ Eastern Mediterranean } & \multicolumn{3}{|c|}{ Black Sea } \\
\hline & Frequency & Depth & Area & Frequency & Depth & Area & Frequency & Depth & Area \\
\hline January & -0.08 & -0.34 & -0.34 & -0.04 & -0.2 & -0.44 & $-\mathbf{0 . 5 3}$ & -0.27 & -0.27 \\
\hline February & -0.34 & -0.22 & -0.28 & -0.06 & -0.22 & -0.27 & -0.3 & -0.2 & -0.26 \\
\hline March & -0.16 & $-\mathbf{0 . 3 3}$ & -0.31 & -0.15 & -0.24 & -0.37 & -0.27 & -0.4 & -0.46 \\
\hline Mean & -0.2 & -0.3 & -0.31 & -0.1 & -0.22 & -0.36 & -0.38 & -0.29 & $-\mathbf{0 . 3 3}$ \\
\hline
\end{tabular}

Table 2. Mean correlation coefficients between the SOI and January-March characteristics of cyclones (lag 5-7 months). All coefficients are significant on $90 \%$ confidence level.

\begin{tabular}{lccc}
\hline Cyclones' characteristics & Black Sea region & Western Mediterranean & Eastern Mediterranean \\
\hline Frequency & +0.39 & +0.32 & +0.34 \\
Area & -0.46 & -0.43 & -0.25 \\
Depth & -0.33 & -0.42 & -0.29 \\
\hline
\end{tabular}

\section{Interannual variability}

Role of the North Atlantic Oscillation and El Nino-Southern Oscillation in the interannual variability of January-March cyclones' characteristics is discussed in this section.

\subsection{Manifestations of the NAO and ENSO}

The dominant climate pattern of the North Atlantic is NAO. According to the well-known mechanism explained by Hurrell (1995), Polonsky and Voskresenskaya (1994) NAO is responsible for intensification of zonal circulation and for the shift of the North Atlantic storm tracks. In the positive NAO phase storm tracks shift to the Northern Europe and anticyclonic conditions prevail over Central, Southern Europe, and the Mediterranean region, while in its negative phase most of storm tracks displace to the Eastern Europe and Mediterranean region and more anticyclones occur over the Northern Europe.

To estimate the NAO influence on interannual variability of cyclonic activity in the Mediterranean-Black Sea region, a correlation analysis was done. Table 1 demonstrates the negative correlation coefficients between the NAO index and cyclones' characteristics in January-March and confirms the veracity of above-mentioned NAO mechanism of regulation of European climate anomalies. It was corroborated that NAO has significant responses in all studied regions. However, there are some differences in the Black Sea and Mediterranean regions. For the Black Sea region the most significant correlations are between NAO index and frequency of cyclones, while for the Western and Eastern Mediterranean region significant correlations are only for depth and area of cyclones. There are only few significant correlations with the frequency of cyclones in both parts of the Mediterranean region. This result is corroborated by similar findings by Guijarro et al. (2006). The mean correlation coefficients are in the lowest line of Table 1.

The maximum negative correlation is between frequency of the Black Sea cyclones in January and NAO index $(r=$ $-0.53)$. In this case the coefficient of determination $\left(r^{2}\right)$ is 0.28 which means that the NAO explains up to $28 \%$ of the cyclones' frequency variation. Similarly NAO causes up to $15-20 \%$ of the depth and area variability in the Black Sea region in January-March. As for the Mediterranean region NAO is responsible for up to $12 \%$ of depth and area of cyclones' variance in its western part in January and for up to $20 \%$ of area's variance in its eastern part. These results show that NAO manifests stronger in frequency of Black Sea cyclones and depth and area of Mediterranean cyclones. This fact may be explained that Mediterranean is a region of strong cyclogenesis which makes noisy the global climatic mode in comparison with the Black Sea region.

Correlation analysis of SOI and cyclones' characteristics in January-March revealed the maximum significant correlations on the time lag from 5 to 7 months (see Table 2). Maximum of ENSO teleconnection is for the Black Sea and Western Mediterranean regions. Taking into account the magnitudes of assessed coefficients of determination $\left(r^{2}\right)$, we can conclude that from January to March ENSO is responsible for the 15 to $20 \%$ of total variance of cyclones' characteristics after 5 to 7 months. This lag is due to the delay of maximum Pacific sea surface temperature (SST) anomalies after beginning of an ENSO event. 
The joint influence of the NAO and ENSO can be estimated as a sum of determination coefficients of each these modes separately on the assumption that they are orthogonal. But we decided to confirm the results of summation of determination coefficients with the analysis of multiple linear regressions by the Eq. (1):

$C=p_{1}+p_{2} \cdot I_{\mathrm{NAO}}+p_{3} \cdot I_{\mathrm{SOI}}+\varepsilon$,

where $C$ is an outcome variable or one of cyclones' characteristics in this case; $p_{1}$ is a constant; $p_{2}$ and $p_{3}$ are regression coefficients; $I_{\mathrm{NAO}}$ and $I_{\mathrm{SOI}}$ are independent variables, NAO index and SOI, accordingly; $\varepsilon$ is an estimation error.

Calculated multiple coefficients $R^{2}$ demonstrate that in January-March the NAO and ENSO are responsible for 20$45 \%$ of the cyclones' frequency variance in the Black Sea region, and in the Mediterranean region for not more than $10-25$ and $20-30 \%$ of the depth and area variability, accordingly.

However, the above-mentioned statistics can be improved taking into account the recent results on classification of ENSO events (see for example Horii and Hanawa, 2004; Kao and Yu, 2009; Voskresenskaya and Mikhailova, 2010). This permits to clarify the features of ENSO manifestations in the Mediterranean and Black Sea region.

\subsection{Manifestations of different El Nino types}

Traditionally Southern Oscillation index (SOI) or oceanic ElNino index (SST anomalies in region Nino 3.4) are used as the measure of ENSO intensity. The objective classification of El Nino events was done by Voskresenskaya and Mikhailova (2010) using 152-yr time series of SOI and oceanic index. It was shown that there are at least three types of El Nino which differ one from another in the season of beginning, duration and intensity. These are the spring type (SPR), summer-autumn long (SAL) and summerautumn short types (SAS). Each type has specific manifestations in the North Atlantic - European region. Manifestation in sea level pressure fields are the most important. For instance, " +1 " yr of the SPR type is characterized by a positive NAO phase in January, while of the SAL type - by a negative NAO phase and for the SAS type - by neutral NAO.

Unfortunately, in 1948-2008 there were 8 SPR, 6 SAS and 2 SAL ENSO events. That is why in this case we can analyze monthly anomalies of cyclones characteristics only as the case study. The composites of January storm tracks in the North Atlantic are demonstrated in Fig. 4. During SPR type North Atlantic storm tracks shift northeastwardly (which corresponds to the positive NAO phase). SAL events are accompanied by the shift of storm tracks to the Central Europe and Mediterranean region (as in negative NAO phase). During SAS type the North Atlantic storm tracks are slightly shifted to the North-East (as in neutral NAO).

In order to increase enough the number of degrees of freedom, special time series of January-March cyclones' charac-
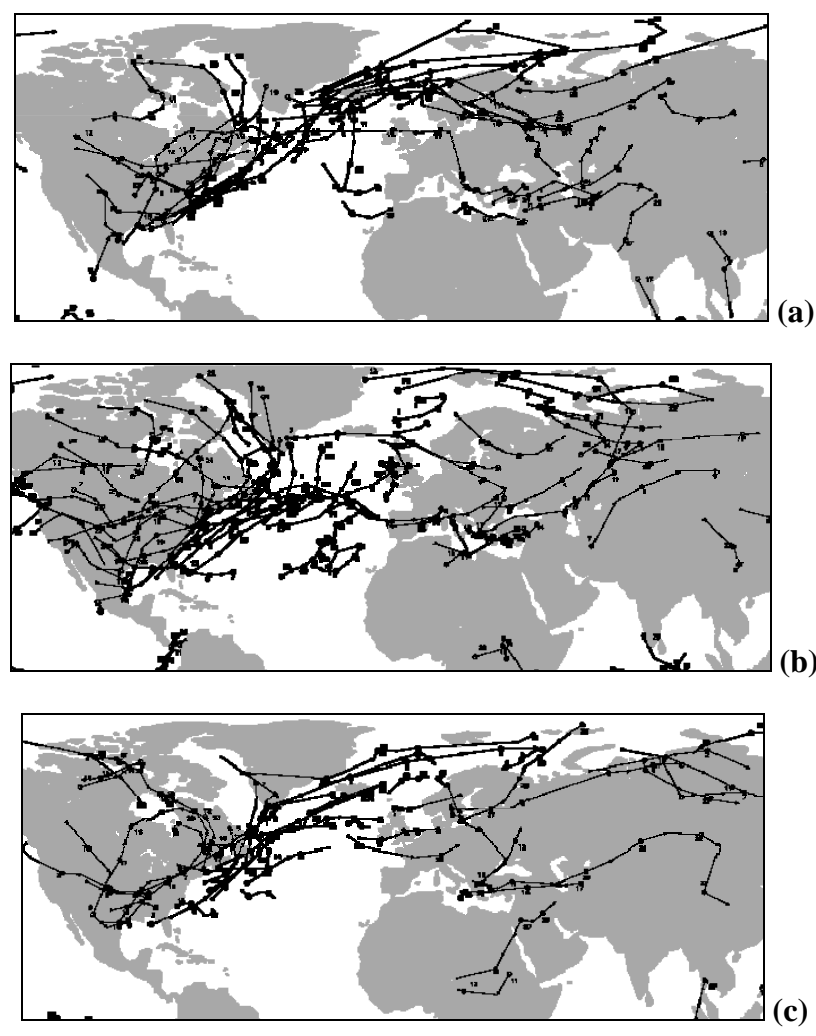

Figure 4. Typical January storm tracks for the " +1 " year of the each type of El Nino on the example of the pair of events: (a) spring type - 1977, 1995; (b) summer-autumn long type - 1969, 1987; (c) summer-autumn short type - 1983, 1998.

teristics were obtained in the following way. Monthly characteristics from January to March were taken consequently for all years with certain El Nino type. Taking into account time lag of 5-7 months, the analogous series of SOI were obtained: Aug-Oct (lag $=5$ months), Jul-Sep (lag $=6$ months), Jun-Aug (lag $=7$ months). This procedure permits to increase enough the number of degrees of freedom of the time series of two types of El Nino (Spring and Summer-Autumn Short) within the correlation analysis. As a result, correlation coefficients between SOI and cyclones' characteristics increased to +0.7 to +0.8 for the SPR type of El Nino and to -0.8 to -0.9 for the SAS type. SAL type was not analyzed because of the mentioned reason. The strong increase of correlation coefficients can be explained as following. If we consider the total number of ENSO events, in this case manifestations of one El Nino type smooth manifestations of the other.

Obtained results highlight that a correct study of ENSO manifestations is possible only taking into account the differences of ENSO types. 


\section{Decadal variability}

Further analysis was focused on decadal and multidecadal variability of cyclones' characteristics associated with the AMO and PDO. Only one period of these oscillations was registered in 1948-2006. That is why composite analysis for their negative and positive phases was done.

\subsection{PDO manifestations}

As it was shown for example in Mantua et al. (1997), PDO is the most prominent quasi-periodical (about 20 to $30 \mathrm{yr}$ ) global climate mode located between 20 and $60^{\circ} \mathrm{N}$ in the Pacific Ocean. It is characterized by alternation of large-scale negative and positive SST anomalies. To estimate PDO manifestations in cyclonic activity in the studied region, composite values of monthly cyclones' characteristics in the periods of negative (1948-1976) and positive (1977-2001) PDO phases were calculated. As an example cyclones' frequency is shown in Fig. 5. In certain winter-spring months cyclonic activity in all parts of the Mediterranean-Black Sea region is significantly (relative to the interannual variability) higher during the negative PDO phase than during the positive one. Particularly, in the Black Sea region JanuaryMarch frequency of cyclones was twice higher during the negative PDO phase. This result is significant on the $95 \%$ confidence level. In negative PDO phase December-April composite values of the area of the Black Sea cyclones exceeded those in positive phase by absolute values, significantly only in February by $\sim 500 \times 10^{3} \mathrm{~km}^{2}$ (90\% confidence level). In the negative PDO phase the depth of cyclones was $\sim 5 \mathrm{hPa}$ greater than in the positive phase (on the $90 \%$ confidence level in February). For the Mediterranean cyclones the response is lower, but still evident in certain months. The frequency of cyclones during the negative PDO phase in the Western Mediterranean was up to $20 \%$ higher in December and March and in the Eastern Mediterranean - in March and October (on $80 \%$ confidence level). Composite values of the other cyclones' characteristics (depth and area) in both parts of the Mediterranean region were greater by absolute values also in winter-spring months during the negative PDO phase.

\subsection{AMO manifestations}

Climatic signal AMO (SST anomaly over the North Atlantic) is the analogue of multidecadal NAO mode. It is characterized by a shift of the North Atlantic storm tracks similar to NAO but with the opposite sign (see for instance Polonsky, 2008). During the positive NAO phase the Icelandic Low and Azores High are mostly shifted to the Northeast, while during the positive AMO phase to Southwest. Associated trajectories of North Atlantic cyclones shift to the Northern Europe or to the Southern Europe and Mediterranean region.

In the result of composite analyses we confirm this abovementioned scheme using NCEP/NCAR reanalysis dataset,
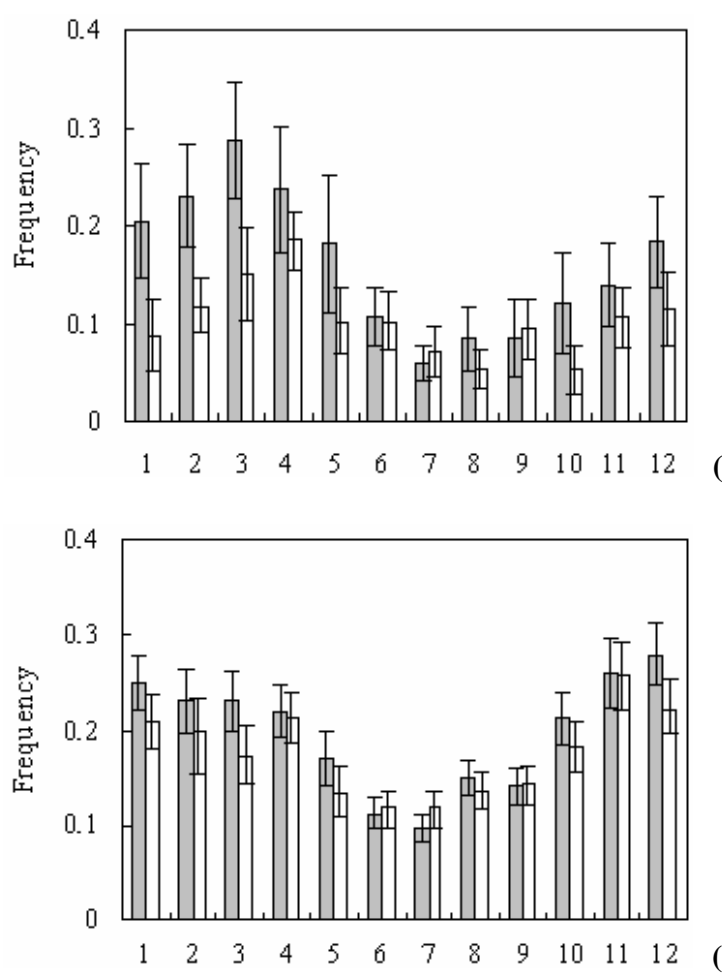

(b)

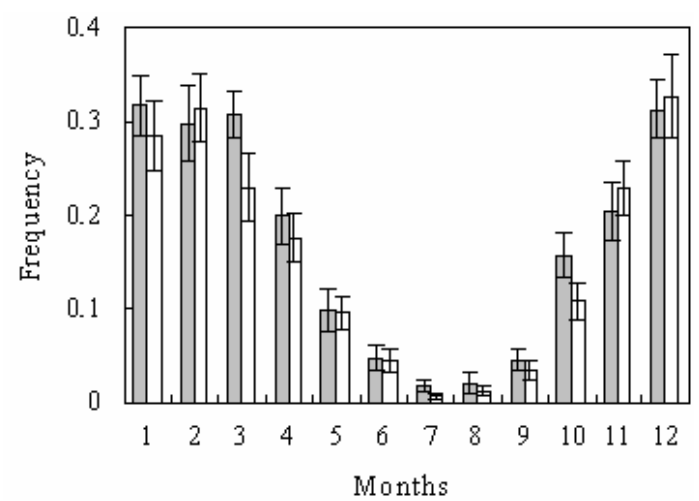

(c)

Figure 5. Composite values of the frequency of cyclones in the (a) Black Sea region, (b) Western Mediterranean and (c) Eastern Mediterranean during the negative (1948-1976) and positive (1977-2001) PDO phase. Confidence level corresponds to the $80 \%$ of statistical significance.

namely composite anomalies of the $500 \mathrm{hPa}$ geopotential height field and the storm tracks in the negative (1971-1975) and positive (1994-1998) AMO phases. During the negative AMO phase there are significant negative anomalies of the $500 \mathrm{hPa}$ geopotential height in the vicinity of the Icelandic Low and positive anomalies in the Azores High (not shown). For this situation the NAO index is positive. That is why 

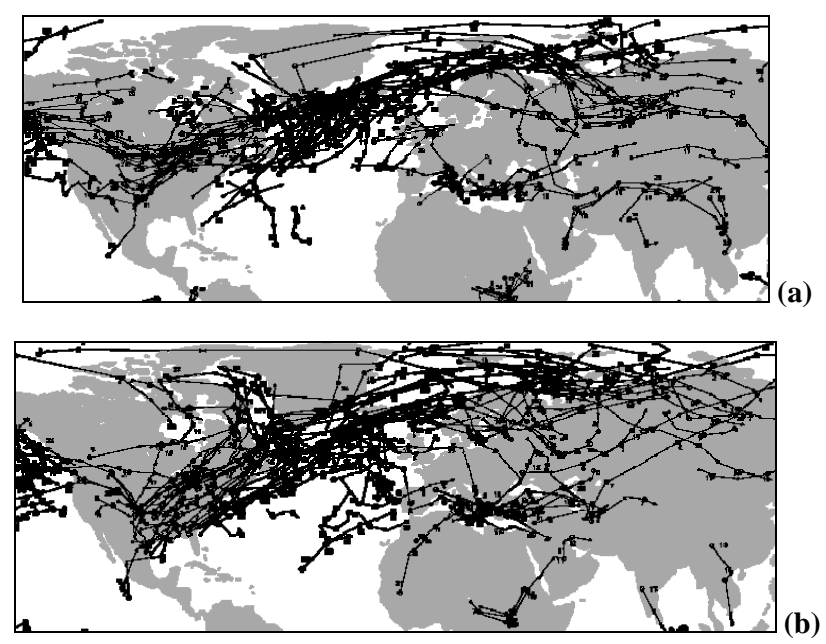

Figure 6. January storm tracks during the periods of the (a) minimum (1971-1975) and (b) maximum (1994-1998) AMO index.

North Atlantic storm tracks move to the North-Eastern part of the North Atlantic, as shown in Fig. 6a. In the Mediterranean region and Central Europe cyclonic activity is low. During the positive AMO phase Icelandic Low is characterized by the positive anomalies of the $500 \mathrm{hPa}$ geopotential height and there are negative anomalies in the Azores High vicinity. Therefore, centers of action of atmosphere in the North Atlantic are weak and the NAO is negative. Figure $6 \mathrm{~b}$ illustrates that during this period cyclonic activity is intensive in the Mediterranean-Black Sea region.

The described mechanism is also confirmed by the positive sign of correlation coefficients between the characteristics of Mediterranean-Black Sea cyclones and unsmoothed AMO index. Correlation analysis was done separately for the periods of the positive (1948-1960) and negative (19661995) AMO phases and for the periods of transition from one phase to another (1960-1975, 1990-2006, accordingly). The maximum correlation coefficients significant on $95 \%$ confidence level (relative to the interannual variability) reach $0.3-$ 0.6 for all analyzed time intervals. On the basis of coefficient of determination it is possible to conclude that up to $36 \%$ of variance of the cyclones' characteristics is associated with the AMO influence.

\section{Conclusions}

As a result of analyses of interannual-multidecadal JanuaryMarch cyclonic variability in the Mediterranean-Black Sea region associated with NAO, ENSO, PDO and AMO the following results were formulated.

NAO manifests mainly in cyclones' frequency variability in the Black Sea region and in depth and area variability in the Western and Eastern Mediterranean. The joint NAO and ENSO influence is responsible for 20-45 \% of cyclones' frequency variance in the Black Sea region, while in the Mediterranean region for up to $10-25$ and $20-30 \%$ of the depth and area variance, accordingly.

Manifestations of three classified El Nino types in cyclones' variability cardinally differ one from another. It is highlighted that ENSO classification is essential in the correct analysis of regional ENSO manifestations.

PDO and AMO have significant (relative to the interannual variability) manifestations in the decadal variability of cyclonic activity in the Mediterranean-Black Sea region from December to March. The negative PDO phase is accompanied by the intensification of cyclonic activity in the comparison with the positive PDO phase in the studied regions. Particularly, cyclones' frequency in the Black Sea region double in the negative PDO phase from January to March. Our research confirms that the AMO considerably influences on the behavior of storm tracks in the Mediterranean-Black Sea region in winter-spring months (December-March), with correlation coefficients up to $+0.3-+0.6$.

\section{Supplementary material related to this article is available online at: http://www.adv-sci-res.net/6/237/2011/ asr-6-237-2011-supplement.pdf.}

Acknowledgements. The authors thank referees and editor for evaluating this paper.

Partly results were obtained within the grant FP7 Collaborative Project “THESEUS”, Grant Agreement No. 244104.

Edited by: S. Gualdi

Reviewed by: two anonymous referees

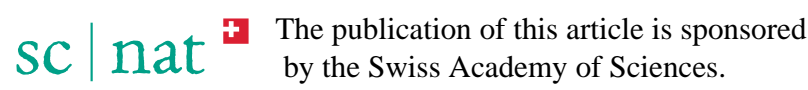

\section{References}

Bardin, M. Yu.: Variability of cyclonic characteristics in the middle troposphere of the North hemisphere midlatitudes, Meteorology and hydrology, 11, 24-37, 1995 (in Russian with English abstract).

Barnston, A. and Livezey, R.: Classification, seasonality and persistence of low-frequency atmospheric circulation patterns, Mon. Weather Rev., 115, 6, 1083-1126, 1987.

Enfield, D. and Mestas-Nunez, A. M.: Multiscale variability in global SST and their relationships with tropospheric climate patterns, J. Climate, 9, 2719-2733, 1999.

Enfield, D. B., Mestas-Nunez, A. M., and Trimble P. J.: The Atlantic Multidecadal Oscillation and its relationship to rainfall and river flows in the continental U.S., Geophys. Res. Lett., 28, 2077-2080, 2001.

Guijarro, J. A., Jansà, A., and Campins, J.: Time variability of cyclonic geostrophic circulation in the Mediterranean, Adv. Geosci., 7, 45-49, doi:10.5194/adgeo-7-45-2006, 2006. 
Horii, T. and Hanawa, K.: A relationship between timing of El Nino onset and subsequent evolution, Geophys. Res. Lett., 31, 1634$1648,2004$.

Hurrell, J. W.: Decadal trends in the North Atlantic Oscillation and relationships to regional temperature and precipitation, Science, 269, 676-679, 1995.

Kao, H. Y. and Yu, J. Y.: Contrasting eastern Pacific and central Pacific types of ENSO, J. Climate, 22, 615-632, 2009.

Kerr R. A.: Atlantic climate pacemaker for millennia past, decades hence? Sience, 5731, 41-42, 2005.

Lionello, P., Bhend, J., Buzzi, A., Della-Marta, P. M., Krichak, S., Jansà, A., Maheras, P., Sanna, A., Trigo, I. F., and Trigo, R.: Cyclones in the Mediterranean region: climatology and effects on the environment, in: Mediterranean Climate Variability, edited by: Lionello, P., Malanotte-Rizzoli, P., and Boscolo, R., Elsevier, Amsterdam, 324-272, 2006.

Mantua, N. J., Hare S. R., Zhang Y., Wallace J. M., and Francis R. C.: A Pacific interdecadal climate oscillation with impacts on salmon production, BAMS, 78, 1069-1079, 1997.

Mariotti, A., Zeng, N., and Lau, K.-M.: Euro-Mediterranean rainfall and ENSO - a seasonally varying relationship, Geophys. Res. Lett., 29, 1621, doi:10.1029/2001GL014248, 2002.

Mathieu, P. P., Sutton, R. T., Dong, B., and Collins, M.: Predictability of winter climate over North Atlantic European region during ENSO events, J. Climate, 17, 1953-1974, 2004.

Pekarova, P., Miklanek, P., and Pekar, J.: Long-term trends and runoff fluctuations of European rivers, Fifth FRIEND World Conference (Havana, Cuba, November 2006), IAHS Publ., p. 308, 2006.

Pinto, J. G., Zacharias, S., Fink, A. H., Leckebusch, G. C., and Ulbrich, U.: Factors contributing to the development of extreme North Atlantic cyclones and their relationship with the NAO, Clim. Dynam., 32, 711-737, 2009.
Polonsky, A. B.: Atlantic multidecadal oscillation and its manifestations in the Atlantic-European region, Marine Hydrophysical Journal, 4, 47-58, 2008 (in Russian with English abstract).

Polonsky, A. and Voskresenskaya, E.: Interannual variability in the Tropical and North Atlantic associated with the Pacific Ocean ENSO events, Contemporary Climatology, Proc. of the Meeting of the Commission on Climatology of the IGU, Brno, 467-472, 1994.

Polonsky, A. B., Bardin, M. Yu., and Voskresenskaya, E. N.: Statistical characteristics of cyclones and anticyclones over the Black Sea in the second half of the 20th century, Physical Oceanography, 17, 348-359, 2007.

Trigo, I. F., Davies, T. D., and Bigg, G. R.: Objective climatology of cyclones in the Mediterranean region, J. Climate, 12, 16851696, 1999.

Trigo, R. M., Pozo-Vazquez, D., Castro-Diez, Y., Osborn, T., Gamis-Fortis, S., and Esteban-Parra, M. J.: NAO influence on precipitation, river flow regimes and hydroelectric power generation in the Iberian peninsula, Geophys. Res. Abstr., 5, 05494, 2003.

Voskresenskaya, E. N.: Variability of the European rivers' runoff associated with global climate processes, Monitoring systems of environment, CSW of NASU, MHI, 144-147, 2003 (in Russian with English abstract).

Voskresenskaya, E. N. and Mikhailova, N. V.: El-Niño classification and climate/weather anomalies in the Black Sea region, Monitoring systems of environment, Reports of the NAS of Ukraine, 3, 120-124, 2010 (in Russian with English abstract). 